\title{
The Impact of Subjective and Objective Social Status on Depression in a Cohort of Graduate-Level Students
}

\author{
Carol Vidal1', Whitney Brown ${ }^{2}$, Flavius R. W. Lilly ${ }^{2 *}$ \\ ${ }^{1}$ Department of Child and Adolescent Psychiatry, Johns Hopkins University School of Medicine, Baltimore, USA \\ ${ }^{2}$ University of Maryland Graduate School, Baltimore, USA \\ Email: *Flilly@umaryland.edu
}

How to cite this paper: Vidal, C., Brown, W. and Lilly, F.R.W. (2018) The Impact of Subjective and Objective Social Status on Depression in a Cohort of Graduate-Level Students. Open Journal of Social Sciences, 6, 287-301.

https://doi.org/10.4236/jss.2018.65021

Received: May 3, 2018

Accepted: May 28, 2018

Published: May 31, 2018

Copyright (c) 2018 by authors and Scientific Research Publishing Inc. This work is licensed under the Creative Commons Attribution International License (CC BY 4.0).

http://creativecommons.org/licenses/by/4.0/

\begin{abstract}
This study examined the associations of subjective social status (SSS), objective measures of socio-economic status (SES), and depression among graduate-level college students. This cross-sectional study surveyed 800 graduate-level students attending a major public research university in the Mid-Atlantic region of the United States. SSS was derived from the MacAuthur Scale of Subjective Social Status, SES from respondents' parental income and education, and depression from the Patient Health Questionnaire-2. Multivariate logistic regression analysis was used to examine the relationship between SSS, SES, and depression controlling for covariates. The overall prevalence of depression in the sample was $11.1 \%$. Regression modeling demonstrated that low SSS was predictive of depression $(\mathrm{OR}=0.65 ; 95 \%$ CI: 0.56 0.77 ) whereas all objective measures of SES were non-significant. Low SSS is a relevant risk factor for depression and should be considered in mental health counseling and academic advising of graduate-level students as it may be amenable to intervention.
\end{abstract}

\section{Keywords}

Subjective Social Status, Socioeconomic Status, Depression, Graduate Students, Mental Health

\section{Introduction}

The mean prevalence of depressive disorders among college students may be as high as $30.6 \%$ [1]. College students who experience depression are at greater risk for increased abuse of alcohol [2], risk-taking behaviors [3], compulsive gam- 
bling [4], and poor sleep habits [5]. They are also at greater risk for academic failure [6]. Accordingly, depression and its consequences are of growing concern among college administrators, counselors, and student affairs professionals.

The rate of depression in graduate-level students is similar to their undergraduate counterparts [7] [8] and higher than those of their age matched peers in the general population [8] [9] [10] [11] [12]. In some samples, nearly half of graduate students have reported emotional problems in the past year [13]. These reports demonstrate the substantial prevalence of mental health problems among students regardless of academic level. Yet, most of the research in college students is focused on undergraduate students.

\section{Literature Review on Social status and Mental Health}

Social status operates on a gradient influencing health and well-being, with higher social status protecting against morbidity and mortality [14]. From an evolutionary perspective, humans are thought to have evolved a motivation toward higher status [15] because of its inherent benefits to survival such as resource acquisition and opportunities for reproduction [16]. Threats to status represent a source of chronic stress that may modify neuroendocrine function resulting in depression [17].

Subjective social status (SSS) has been defined as "a person's belief about his location in a status order" [18]. SSS is, in other words, one's judgement of their "prestige" in comparison to others in their social group [19]. In studies assessing mental health issues among students, SSS is rarely considered. This is because social status has largely been operationalized in terms of objective socioeconomic measures like education, income and occupation. Yet, these indicators represent only one dimension of the social gradient. Consequently, SSS has been suggested as a preferable indicator [20] [21] as it considers psychosocial dimensions of health.

Adler and Stewart [22] advocate for a developmental approach to understanding social status that reflects the contextual environment in which the individual resides. Consideration of context may help disentangle the mechanisms through which status impacts well-being. These mechanisms are not yet sufficiently explored in young adult populations, and there is a dearth of research in the unique context of graduate-level education. Graduate students encounter significant stressors and are at an important transition in their lives as they are being professionalized in their respective disciplines, potentially altering their awareness of social rank.

Little is known about how individuals subjectively determine their own status. The "cognitive averaging" concept [23] has been suggested as the method by which individuals rank themselves in the social status hierarchy by making a global assessment of several socio-economic factors. However, recent research among young adults suggests that traditional factors such as income, education, and occupation may be insufficient variables to consider in cognitive averaging. Rather, family background, grade point average, college selectivity, parenthood 
and perhaps a host of other variables may be important to perceived status [24]. Hence, it is important to better understand the factors that influence one's subjective assessment of social rank across developmental stages when examining health outcomes. Elucidating these pathways has implications for the development of effective interventions to improve mental health outcomes and academic success.

To our knowledge, this is the first study to examine depression and SSS in a population of graduate-level students. The study examined this relationship by controlling for sociodemographic and traditional, more objective socioeconomic indicators. We hypothesized that those students with a lower SSS would report symptoms of depression more than those who rank themselves higher in SSS. We also hypothesized that SSS would play a more significant role in predicting depression than objective socioeconomic measures. Research in this area is needed to improve the understanding of the factors that predispose graduate-level students to depression. This understanding can be used to inform mental health promotion in the context of graduate-level education and professionalization.

\section{Data and Methods}

\subsection{Study Design}

This observational cross-sectional study was conducted using an anonymous online questionnaire. Currently enrolled students of a large public university in the Mid-Atlantic region ( $\mathrm{N}=6741)$ were invited to participate via email. The inclusion criteria indicated respondents must be over the age of 18 years, enrolled in a graduate program and agreeing to participate. Participants were given two weeks to complete the questionnaire and gave implicit consent by reading the explanatory introduction and completing the survey. A total of 998 students participated with 800 providing complete data, yielding a response rate of $11.9 \%$. The study was approved by the University's Institutional Review Board.

\subsection{Instruments and Data}

The questionnaire was composed of previously validated measures to assess SSS, socio-economic status, and depression. The MacArthur Scale of Subjective Social Status was used to assess SSS. This scale is presented in a ladder format and asks individuals to select the rung on which they feel they stand in relation to others in their community. An image of a ladder with 10 rungs was presented and participants were asked to "Think of the ladder in the image as representing where people stand in their communities. People define community in different ways; please define it in whatever way is most meaningful to you". The instructions specified the meaning of the top and bottom rungs, "At the top of this ladder are the people who have the highest standing in their community. At the bottom are the people who have the lowest standing in their community". Participants were asked "Where would you place yourself on this ladder? Please choose the rung 
on the ladder that represents where you think you stand at this time in your life, relative to other people in your community" [23]. In a previous study, intraclass correlation for the SSS ladder was 0.56 (95\% CI: 0.22 - 0.90) and Kappa was 0.54 (95\% CI: 0.44 - 0.59) in a test-retest assessment [25].

To assess objective measures of social status, respondents' sociodemographic, educational, and childhood socioeconomic level were considered. Sociodemographic factors included age, gender (male or female), and race (White, Black, Hispanic, Asian, and Other). Educational factors included year of study (incoming, first year, second year, third year, fourth year or more). Childhood socioeconomic factors included mother's and father's educational level ( $\leq$ high school, $\leq$ Associate's degree, $\geq$ Bachelor's degree, $\geq$ Master's degree), and mother's and father's median annual earnings based on the U.S. Department of Labor statistics on occupational income.

The primary outcome measure for this analysis was case-level depressive symptoms defined by a score of three or greater on the two-item Patient Health Questionnaire-2 (PHQ-2). The PHQ-2 asks about the frequency of depressed mood and anhedonia over the past two weeks. The questions asked in the PHQ-2 are "Over the past two weeks, how often have you been bothered by any of the following problems: 1) Little interest or pleasure in doing things; and 2) Feeling down, depressed or hopeless" [26]. Each question on the PHQ-2 ranges from 0 - $3(0=$ not at all, $1=$ several days, $2=$ more than half the days, and $3=$ nearly every day) and the overall PHQ-2 score ranges from $0-6$. Kroenke, Spitzer, and Williams [27] have identified a cutoff score of 3 as the optimal cut-point for depression screening, with those scoring 3 or above meeting screening criteria with a sensitivity of $83 \%$ and specificity of $92 \%$ for major depression. In our sample, internal consistency for the PHQ-2 Depression Scale exhibited good reliability with a Cronbach $\alpha=0.891$, indicating high consistency for this scale in this sample. Previously, the PHQ-2 has shown a sensitivity of $81 \%$ and a specificity of $96 \%$ with an internal consistency of 0.727 (95\% CI: $0.690-0.759)$ and a concurrent validity of $r=0.61(p<0.001)$ [28].

\subsection{Analytical Methods}

The purpose of this study was to examine participants' current assessment of their SSS and SES and determine the relationship of these variables with depression. Descriptive statistics were computed including a description of sample characteristics of the population, computed frequencies and percentages, means, and standard deviations. Next, a univariate logistic regression was performed for each variable. Logistic regression coefficients were converted to odds ratios and used to interpret the effects of each variable. Finally, a multivariate logistic regression analysis was performed to analyze the contributions of predictor variables to the dichotomous outcome variable of depression. Data for the logistic regression was loaded in the following order and included: 1) Demographic and SSS characteristics including the MacArthur SSS indicator, age, gender, race, and 
whether participants were born in the United States; 2) Year of Study; and 3) Childhood socioeconomics including each parent's educational level, and each parent's income level derived from the U.S. Department of Labor statistics on occupational income. Independent and interaction effects of all coded variables were computed and analyzed using SPSS, Version 23. Suspected interactions of the demographic variables specifically, were retained in the logistic regression model if they reached significance beyond $p<0.05$. However, there were no significant interaction effects detected in the current study.

\section{Results}

\subsection{Sample Characteristics}

The sample consisted of 800 graduate and professional students (mean age 28.4 years; SD 7.4 years, range between 19 and 61 years; 77.4\% women). The overall prevalence of depression in the sample was $11.1 \%(n=89)$, which is consistent with findings from previous research [8]. Students ranked themselves in the 10-rung SSS ladder with a mean of $6.32(\mathrm{SD}=1.52)$. Depressed students ranked themselves in the SSS ladder with a mean of $5.45(\mathrm{SD}=1.69)$ while non-depressed students mean rank in the SSS ladder was $6.43(\mathrm{SD}=1.46)$ indicating higher perceived social status among the non-depressed group. Table 1 summarizes the sample characteristics and illustrates that as SSS increased, the risk of depression significantly decreased ( $O R=0.6 ; 95 \%$ CI: 0.58 - 0.77).

More than half of the sample (59.4\%) were white students, $14.5 \%$ were African American, 5.0\% Hispanic, 15.3\% Asian, and 5.9\% of other races/ethnicities. Black and Hispanic students tended to be significantly more depressed than students of other ethnicities with an OR $=1.97$ (95\% CI: 1.10 - 3.53) among Blacks and OR $=2.51$ (95\% CI: 1.09 - 5.79) among Hispanics compared to White respondents. Depression did not differ by students' disciplines and close to one-fourth of the respondents were studying social work (26.3\%), followed by nursing (20.3\%), graduate students pursuing master's in science (MS) or doctor in philosophy $(\mathrm{PhD})$ degrees (15.3\%), medicine (15.0\%), law (9.1\%), pharmacy (8.0\%), and dentistry (6.0\%). Nearly one-third of students were in their first year of study (31.8\%), followed by second-year students (29.0\%), third-year students (16.0\%), fourth-year students (12.8\%), and newly matriculating incoming students $(10.5 \%)$. The majority $(70 \%)$ of students surveyed grew up in suburban homes, followed by urban (16.8\%) and rural (13.3\%) homes. Maternal education was evenly distributed among those with less than High School level completed (23.5\%), less or equal to an Associate's degree (23.2\%), less or equal to a Bachelor's degree $(25.3 \%)$, and higher than a Master's degree (28\%). The majority (35.6\%) had fathers with an education level of a Master's degree or higher, followed by Bachelor's degree or less (24.7\%), Associate's degree or less (18.6\%) and High School degree or less $(21.1 \%)$. The majority (45.3\%) had a maternal annual income between $\$ 42,791$ and 65,710 . The highest percentage (32.3\%) fell within the bracket of paternal annual income between $\$ 30,091$ and 42,790 . 
Table 1. Sample characteristics among those respondents with $(n=89)$ and without $(n=$ 711) depression displaying unadjusted odds ratios for between group differences.

\begin{tabular}{|c|c|c|c|c|c|c|c|c|}
\hline & & \multicolumn{2}{|c|}{ All Sample } & \multicolumn{2}{|c|}{ Not Depressed } & \multicolumn{2}{|c|}{ Depressed } & \multirow{2}{*}{$\begin{array}{l}\text { Unadjusted } \\
\text { Odds Ratio }\end{array}$} \\
\hline & & $\mathrm{n}^{\mathrm{a}}$ & $\%^{\mathrm{b}}$ & $\mathrm{n}^{\mathrm{a}}$ & $\%^{\mathrm{b}}$ & $\mathrm{n}^{\mathrm{a}}$ & $\%^{\mathrm{b}}$ & \\
\hline SSS & Mean (SD) & 6.32 & $(1.52)$ & 6.43 & $(1.46)$ & 5.45 & (1.69) & $0.67^{\star * \star}$ \\
\hline \multirow{2}{*}{ Gender } & Male & 176 & 22.0 & 157 & 89.2 & 19 & 10.8 & reference \\
\hline & Female & 619 & 77.4 & 551 & 89.0 & 68 & 11.0 & 1.02 \\
\hline \multirow{5}{*}{ Race } & White & 475 & 59.4 & 432 & 90.9 & 43 & 9.1 & reference \\
\hline & Black & 116 & 14.5 & 97 & 83.6 & 19 & 16.4 & $1.97^{\star}$ \\
\hline & Hispanic & 40 & 5.0 & 32 & 80.0 & 8 & 20.0 & $2.51^{\star}$ \\
\hline & Asian & 122 & 15.3 & 110 & 90.2 & 12 & 9.8 & 1.10 \\
\hline & Other & 47 & 5.9 & 40 & 85.1 & 7 & 14.9 & 1.75 \\
\hline \multirow{2}{*}{ U.S. Born } & No & 125 & 15.6 & 109 & 87.2 & 16 & 12.8 & reference \\
\hline & Yes & 675 & 84.4 & 602 & 89.2 & 73 & 10.8 & 0.83 \\
\hline \multirow[t]{3}{*}{ Age (years) } & Mean (SD) & 28 & $(7.4)$ & 28.4 & $(7.3)$ & 28.1 & $(8.1)$ & 0.99 \\
\hline & Incoming & 84 & 10.5 & 77 & 91.7 & 7 & 8.3 & reference \\
\hline & First & 254 & 31.8 & 219 & 86.2 & 35 & 13.8 & 1.76 \\
\hline \multirow[t]{4}{*}{ Study Year } & Second & 232 & 29.0 & 210 & 90.5 & 22 & 9.5 & 1.15 \\
\hline & Third & 128 & 16.0 & 110 & 85.9 & 18 & 14.1 & 1.80 \\
\hline & $\geq$ Fourth & 102 & 12.8 & 95 & 93.1 & 7 & 6.9 & 0.81 \\
\hline & Urban & 134 & 16.8 & 115 & 85.8 & 19 & 14.2 & reference \\
\hline \multirow[t]{3}{*}{ Childhood Home } & Suburban & 560 & 70.0 & 500 & 89.3 & 60 & 10.7 & 1.58 \\
\hline & Rural & 106 & 13.3 & 96 & 90.6 & 10 & 9.4 & 1.15 \\
\hline & $\leq$ High School & 186 & 23.5 & 163 & 87.6 & 23 & 12.4 & reference \\
\hline \multirow{4}{*}{$\begin{array}{l}\text { Maternal } \\
\text { Education }\end{array}$} & $\leq$ Associate's & 183 & 23.2 & 167 & 91.3 & 16 & 8.7 & 0.67 \\
\hline & $\leq$ Bachelor's & 200 & 25.3 & 180 & 90.0 & 20 & 10.0 & 0.78 \\
\hline & $\geq M . S$. & 221 & 28.0 & 191 & 86.4 & 30 & 13.6 & 1.11 \\
\hline & $\leq$ High School & 164 & 21.1 & 148 & 90.2 & 16 & 9.8 & \\
\hline \multirow{4}{*}{$\begin{array}{c}\text { Paternal } \\
\text { Education }\end{array}$} & $\leq$ Associate's & 144 & 18.6 & 132 & 91.7 & 12 & 8.3 & 0.84 \\
\hline & $\leq$ Bachelor's & 192 & 24.7 & 169 & 88.0 & 23 & 12.0 & 1.26 \\
\hline & $\geq M . S$ & 276 & 35.6 & 239 & 86.6 & 37 & 13.4 & 1.43 \\
\hline & $\leq \$ 30,090$ & 145 & 18.6 & 131 & 90.3 & 14 & 9.7 & reference \\
\hline \multirow{4}{*}{$\begin{array}{l}\text { Maternal Annual } \\
\text { Income }\end{array}$} & $\$ 30,091-42,790$ & 206 & 26.4 & 174 & 84.5 & 32 & 15.5 & 1.72 \\
\hline & $\$ 42,791-65,710$ & 353 & 45.3 & 322 & 91.2 & 31 & 8.8 & 0.91 \\
\hline & $\$ 65,711-100 \mathrm{k}+$ & 75 & 9.6 & 65 & 86.7 & 10 & 13.3 & 1.44 \\
\hline & $\leq \$ 30,090$ & 112 & 14.3 & 98 & 87.5 & 14 & 12.5 & reference \\
\hline \multirow{3}{*}{$\begin{array}{l}\text { Paternal Annual } \\
\text { Income }\end{array}$} & $\$ 30,091-42,790$ & 252 & 32.3 & 227 & 90.1 & 25 & 9.9 & 1.11 \\
\hline & $\$ 42,791-65,710$ & 220 & 28.2 & 190 & 86.4 & 30 & 13.6 & 0.75 \\
\hline & $\$ 65,711-100 \mathrm{k}+$ & 197 & 25.2 & 178 & 90.4 & 19 & 9.6 & 0.14 \\
\hline
\end{tabular}

${ }^{*} \mathrm{p} \leq 0.05 ;{ }^{* *} \mathrm{p} \leq 0.01 ;{ }^{* * *} \mathrm{p} \leq 0.001 ;{ }^{\mathrm{a}}$ Unweighted counts; ${ }^{\mathrm{b}}$ Weighted percentages. 
Table 2. Correlation matrix of all independent predictor variables and depression $(\mathrm{N}=800)$.

\begin{tabular}{|c|c|c|c|c|c|c|c|c|c|c|}
\hline & (1) & (2) & (3) & (4) & (5) & (6) & (7) & (8) & (9) & (10) \\
\hline 1) Subjective Social Status & 1 & & & & & & & & & \\
\hline 2) Age & 0.07 & 1 & & & & & & & & \\
\hline 3) Gender & -0.04 & -0.04 & 1 & & & & & & & \\
\hline 4) U.S. Born & -0.02 & $-0.12^{*}$ & 0.06 & 1 & & & & & & \\
\hline 5) Race & 0.04 & 0.03 & -0.01 & $-0.40^{* * *}$ & 1 & & & & & \\
\hline 6) Year of Study & $0.07^{*}$ & $0.24^{* * *}$ & $-0.12^{\star *}$ & $-0.09^{*}$ & 0.04 & 1 & & & & \\
\hline 7) Maternal Education & 0.01 & $-0.12^{\star * *}$ & -0.04 & 0.06 & $-0.14^{* * *}$ & 0.02 & 1 & & & \\
\hline 8) Paternal Education & 0.02 & -0.06 & $-0.09^{* *}$ & 0.02 & $-0.08^{*}$ & 0.03 & $0.55^{\star * *}$ & 1 & & \\
\hline 9) Maternal Earnings & -0.01 & -0.02 & $-0.07^{\star}$ & -0.02 & $-0.09^{*}$ & -0.01 & $0.45^{\star * *}$ & $0.22^{* * *}$ & 1 & \\
\hline 10) Paternal Earnings & 0.06 & $-0.09^{*}$ & $-0.08^{\star}$ & 0.04 & -0.07 & -0.01 & $0.29^{* * *}$ & $0.50^{* * *}$ & $0.24^{\star * *}$ & 1 \\
\hline Depression (PHQ-2) & $-0.19^{\star * *}$ & -0.05 & 0.01 & -0.02 & $0.07^{*}$ & -0.02 & 0.02 & 0.06 & -0.02 & -0.01 \\
\hline
\end{tabular}

${ }^{*} \mathrm{p} \leq 0.05 ;{ }^{* *} \mathrm{p} \leq 0.01 ;{ }^{* * *} \mathrm{p} \leq 0.001$.

Table 2 shows the bivariate Pearson's correlations on baseline measures of SSS, age, gender, U.S. born, race, year of study, parents' education and income, and depression. SSS was positively correlated with year of study $(0.07 ; \mathrm{p} \leq 0.05)$. There was a weak but significant negative correlation between SSS and depression $(-0.187 ; \mathrm{p} \leq 0.0001)$. No other independent variables were correlated with depression.

\subsection{Multivariate Analysis}

The multiple logistic regression model predicting depression (Table 3 ) yielded an $\mathrm{R}^{2}=0.166$ and mirrored the results of univariate statistics yielding significant associations between SSS and depression with the odds of depression increasing with lower SSS. Race remained a significant predictor of depression in multivariate regression with Black and Hispanic participants again having higher odds of depression at 3.28 [95\% CI: 1.58 - 6.82] and 3.93 [95\% CI: 1.47 - 10.47], respectively compared to White participants. Asian participants and participants of other races did not have significantly higher odds of depression compared to Whites. Age, gender, country of birth, year of study, maternal education and income, and paternal education and income were not significantly associated with depression among graduate-level students. The regression analysis indicated that objective measures of SES like participant's parent's annual earnings and education did not contribute significantly to models predicting depression. Independent variables were initially loaded in blocks as indicated in the methods, however, this loading procedure did not produce any relevant information compared to a final model with all the variables, as presented in Table 3. Additionally, there were no significant interactions effects detected.

\section{Discussion}

This study shows that respondents with depression constitute a sizable portion 
Table 3. Multiple logistic regression model demonstrating low SSS as a risk factor for depression among graduate-level students $(\mathrm{N}=800)$.

\begin{tabular}{|c|c|c|c|c|}
\hline Predictor Variables & $\beta$ & S.E. & $O R$ & $95 \% \mathrm{CI}$ \\
\hline Subjective Social Status & -0.43 & 0.08 & $0.65^{\star * *}$ & $0.56-0.77$ \\
\hline Age & -0.02 & 0.02 & 0.98 & $0.95-1.02$ \\
\hline Gender $($ ref $=$ males $)$ & -0.08 & 0.31 & 0.93 & $0.51-1.67$ \\
\hline Born in USA $(r e f=n o)$ & -0.11 & 0.38 & 0.90 & $0.43-1.88$ \\
\hline \multicolumn{5}{|l|}{ Race $(r e f=$ white $)$} \\
\hline Black & 1.19 & 0.37 & $3.28^{* * *}$ & $1.58-6.82$ \\
\hline Hispanic & 1.37 & 0.50 & $3.93^{* *}$ & $1.48-10.48$ \\
\hline Asian & 0.20 & 0.41 & 1.222 & $0.55-2.72$ \\
\hline Other & 0.86 & 0.48 & 2.35 & $0.91-6.07$ \\
\hline \multicolumn{5}{|l|}{ Year (ref = Incoming) } \\
\hline First Year & 0.76 & 0.49 & 2.13 & $0.81-5.59$ \\
\hline Second Year & 0.35 & 0.52 & 1.41 & $0.51-3.92$ \\
\hline Third Year & 0.83 & 0.53 & 2.29 & $0.81-6.47$ \\
\hline$\geq$ Fourth Year & 0.27 & 0.61 & 1.31 & $0.40-4.33$ \\
\hline \multicolumn{5}{|l|}{ Maternal Education $(r e f=\leq H . S$. $)$} \\
\hline Associate's/Some College & -0.42 & 0.41 & 0.657 & $0.30-1.46$ \\
\hline Bachelors/Some Grad & -0.20 & 0.43 & 0.817 & $0.36-1.88$ \\
\hline Earned M.S. or Doctorate & 0.01 & 0.43 & 1.008 & $0.44-2.32$ \\
\hline \multicolumn{5}{|l|}{ Paternal Education $(r e f=\leq$ H.S. $)$} \\
\hline Associate's/Some College & 0.30 & 0.45 & 1.351 & $0.56-3.29$ \\
\hline Bachelors/Some Grad & 0.44 & 0.46 & 1.548 & $0.62-3.87$ \\
\hline Earned M.S. or Doctorate & 0.78 & 0.48 & 2.172 & $0.85-5.56$ \\
\hline \multicolumn{5}{|l|}{ Maternal Earnings ( $r e f=\leq \$ 30,090)$} \\
\hline$\$ 30,091-\$ 42,790$ & 0.55 & 0.38 & 1.72 & $0.82-3.66$ \\
\hline$\$ 42,791-\$ 65,710$ & -0.19 & 0.40 & 0.83 & $0.38-1.82$ \\
\hline$\$ 65,711-\geq \$ 100,000$ & 0.30 & 0.50 & 1.35 & $0.51-3.62$ \\
\hline \multicolumn{5}{|l|}{ Paternal Earnings ( $r e f=\leq \$ 30,090$ ) } \\
\hline$\$ 30,091-\$ 42,790$ & 0.07 & 0.42 & 1.07 & $0.47-2.44$ \\
\hline$\$ 42,791-\$ 65,710$ & 0.39 & 0.48 & 1.48 & $0.58-3.80$ \\
\hline$\$ 65,711-\geq \$ 100,000$ & 0.17 & 0.49 & 1.19 & $0.46-3.07$ \\
\hline-2 Log Likelihood & 456.26 & & & \\
\hline Cox \& Snell $\mathrm{R}^{2}$ & 0.08 & & & \\
\hline Negelkerke $\mathrm{R}^{2}$ & 0.17 & & & \\
\hline Homer \& Lemeshow $\chi^{2}(\mathrm{p})$ & $8.55(\mathrm{p}=$ & & & \\
\hline
\end{tabular}

Notes: ${ }^{*} \mathrm{p} \leq 0.05 ;{ }^{* *} \mathrm{p} \leq 0.01 ;{ }^{* *} \mathrm{p} \leq 0.001$. 
of the graduate student population. Lower SSS was associated with higher rates of depression and expands previous findings [23] [29] [30] [31] of this association to a population of American graduate students. These results are consistent with previous findings in which objective socioeconomic measures like income and education were not as relevant in predicting health outcomes compared to subjective measures of status.

In this study, Black and Hispanic students showed higher rates of depressive symptoms, consistent with previous research showing greater psychological distress among minority students seeking college counseling services at intake and after treatment [32]. Minority Black and Latino students face additional social stressors [33] that could contribute to depression. Additionally, minority young adults experience different SSS trajectories with a tendency for their SSS to decrease from adolescence into adulthood [34]. Furthermore, the "cognitive averaging" principle proposed to describe the assessment the individual derives of their socio-economic resources [20] involves an averaging of one's socio-economic status across time (in the past, present and future) and not just an average of the present social status. This cognitive averaging has been found to be culture-dependent [15]. Some cultures across different countries (such as US vs Japan) place more emphasis on the present than in the past, making the individual's current socio-economic status more or less relevant. This variability in the time emphasis when assessing one's social status could potentially also vary among different ethnicities within the same country. Additionally, those students who come from poorer but less diverse communities may find themselves exposed to peers who rank higher in social status for the first time while in college.

Understanding the effects of social status in humans requires examination of their complex and diverse environment but also consideration of their stage of development. Rosenberg and Pearlin [35] found differences in self-esteem related to social status according to age, with no association among pre-adolescents, a modest relationship among adolescents and a solid relationship among adults, who are more conscious of economic inequality. More recent studies in adolescents have found low SSS to be linked to depression [34] and risky behaviors such as substance abuse [36]. The points of reference for social comparison also differ in adolescents and adults [37].

According to social comparison process theory [38], people who make comparisons would be happier if they were better off than their group of comparison, as this would improve their self-esteem. High frequency of social comparisons has also been linked to negative emotions, independent of self-esteem [39]. Those people who tend to look at others to appraise their self-worth may be more vulnerable to experience negative affect. Situations in which the environment is changing more rapidly, such as transitions in graduate-level education, may involve a higher risk for students who are more prone to making social comparisons. 
The association between status and general health has bidirectional effects [40], with low social status causing poorer health but poor health also decreasing social status. The association between SSS and depression is also probably bidirectional and moderated by other factors [41]. People with a tendency to see the world from a negative lens may be more predisposed to be depressed and rank themselves lower in the social status hierarchy. However, it could also be that perceiving oneself to be lower in social rank predisposes one to depression. Schubert, Süssenbach, Schäfer and Euteneuer [42] conducted an experimental study to assess the impact of manipulating SSS on negative cognitive style, depressive cognition, and rumination to better understand the mechanisms of this relationship. This study found that temporarily low SSS did not change cognitive style but did contribute to depressive cognition and rumination, which are antecedents to depression. Operario, Adler and Williams [43] have previously examined negative affect as a precursor to self-assessment of lower SSS and found that negative affect may be a moderating factor between SSS and health but does not confound their association.

The impact of SSS on depression may have implications for academic achievement because students with higher SSS are less emotionally distressed [44]. In fact, depression has been found to be a mediator between SSS and study skills in high school students. Additionally, because depression often manifests with feelings of hopelessness, a student's perceived outlook of the future may be negatively impacted by low SSS [45]. The results of this study point to a need to consider SSS in both mental health counseling and academic advising of students in graduate studies. While societal factors are known to contribute to mental illness, they are not a common focus in client interviews with mental health professionals and academic advisors. In light of our findings, understanding the relationship between SSS and its impact on the mental health of students opens opportunities for intervention. In fact, SSS may be more amenable to intervention than other aspects of the social environment [30] because the appraisal an individual makes of their environment can be modified with therapy. Individual psychological treatment approaches to prevent disparities in depression and achievement should include psychoeducation and the modification of cognitive distortions derived from the self-perception of lower social status. At the institutional level, diversifying opportunities to affirm one's identity (ethnical, geographical, and professional) and not only focus on one field of status (financial, academic) may help buffer negative self-perceptions. Facilitating social support and opportunities to establish social connections on campus could also be beneficial, as evidenced by previous research findings showing that social support moderates the relationship between social status and mental health outcomes [46]. Additionally, these potential interventions can be expanded outside the college campus to young adults seeking services in the community.

This study contributes to the literature by exploring SSS in adults engaged in graduate and professional studies, a time of significant professional and aca- 
demic transition. Yet, our study has some limitations. The response rate was low which may have contributed to selection bias. Most of the responders were women and the results may not be transferable to a male population. Additionally, we lacked a measure of respondents' current income. Conventionally among students, however, parental SES is used as a proxy by deriving SES from parental income and education as is the case in the current study. Still, these variables may not have reflected the individual's current social position as some students may be financially independent from their parents at this stage in life. We asked students to compare themselves to others in their community, yet we do not have a clear understanding of how this is self-defined. The students might have compared themselves to the community where they grew up, or they may have transitioned to comparing themselves with peers in the university community. However, the SSS measure aims to be inclusive by looking at perceptions and not objective measures, therefore, how the individual makes the comparison is not as important as how they feel in their chosen context. Another limitation is the use of a cross-sectional study design, which does not allow for a definitive interpretation of the direction of statistical relationships among variables. Students who are depressed may rank themselves lower in social status due to having a negative outlook about the world or themselves because of their depression, or their lower ranking may have led to depression.

Future research should look at the ways SSS affects mood by exploring mechanisms such as shame, self-esteem and frequency of social comparisons, as well as environmental factors that contribute to an increase or mitigation of social comparisons. Furthermore, longitudinal studies are needed to help understand causality, especially in light of the possible reciprocal relationship between SSS and well-being. Cross-cultural studies, studies across developmental stages, and studies evaluating mental health disorders other than depression would also contribute to a better understanding of the effects of SSS on mental health. Moreover, the use of experimental studies should be expanded to understand the mechanisms of lower SSS and mental health. Finally, research looking at moderating variables will be important to guide future interventions.

\section{Conclusion}

This study demonstrates that lower SSS is associated with higher rates of depression in a sample of graduate-level students, a population that tends to be understudied. Additionally, our findings indicate that SSS is a better predictor of depression in graduate students than objective socioeconomic measures of parental education and income. These findings have implications for individual support of students at college counseling centers. Further research is needed to understand the underlying mechanisms of the association between SSS and depression. A better understanding of these mechanisms would shed light into the subtle ways in which people make appraisals about their environment and subsequently perceive their social rank. This would also be useful for mental health 
professionals to respond effectively in therapeutic settings.

\section{References}

[1] Ibrahim, A.K., Kelly, S.J., Adams, C.E. and Glazebrook, C. (2013) A Systematic Review of Studies of Depression Prevalence in University Students. Journal of Psychiatric Research, 47, 391-400. https://doi.org/10.1016/j.jpsychires.2012.11.015

[2] Weitzman, E. (2004) Poor Mental Health, Depression, and Associations with Alcohol Consumption, Harm, and Abuse in a National Sample of Young Adults in College. The Journal of Nervous and Mental Disease, 192, 269-277.

https://doi.org/10.1097/01.nmd.0000120885.17362.94

[3] McNair, L.D., Carter, J.A. and Williams, M.K. (1998) Self-Esteem, Gender, and Alcohol Use: Relationships with HIV Risk Perception and Behaviors in College Students. Journal of Sex \& Marital Therapy, 24, 29-36. https://doi.org/10.1080/00926239808414666

[4] Petry, N.M. and Weinstock, J. (2007) Internet Gambling Is Common in College Students and Associated with Poor Mental Health. American Journal on Addictions, 16, 325-330. https://doi.org/10.1080/10550490701525673

[5] Orzech, K.M., Salafsky, D.B. and Hamilton, L.A. (2011) The State of Sleep among College Students at a Large Public University. Journal of American College Health, 59, 612-619. https://doi.org/10.1080/07448481.2010.520051

[6] Hysenbegasi, A., Hass, S.L. and Rowland, C.R. (2005) The Impact of Depression on the Academic Productivity of University Students. Journal of Mental Health Policy and Economics, 8, 145-151.

[7] Bulmer, S.M., Irfan, S., Barton, B., Vancour, M. and Breny, J. (2010) Comparison of Health Status and Health Behaviors between Female Graduate and Undergraduate College Students. Health Educator, 42, 67.

[8] Eisenberg, D., Gollust, S.E., Golberstein, E. and Hefner, J.L. (2007a) Prevalence and Correlates of Depression, Anxiety, and Suicidality among University Students. American Journal of Orthopsychiatry, 77, 534-542. https://doi.org/10.1037/0002-9432.77.4.534

[9] Dyrbye, L.N., Thomas, M.R. and Shanafelt, T.D. (2006) Systematic Review of Depression, Anxiety, and Other Indicators of Psychological Stress among U.S. and Canadian Medical Students. Academic Medicine, 81, 354-373. https://doi.org/10.1097/00001888-200604000-00009

[10] Garcia-Williams, A., Moffitt, L. and Kaslow, N. (2014) Mental Health and Suicidal Behavior among Graduate Students. Academic Psychiatry, 38, 554-560. https://doi.org/10.1007/s40596-014-0041-y

[11] Stecker, T. (2004) Well-Being in an Academic Environment. Medical Education, 38, 465-478. https://doi.org/10.1046/j.1365-2929.2004.01812.x

[12] Gonzalez, O., Berry, J.T., McKnight-Eily, L.R., Strine, T., Edwards, V.J., Lu, H. and Croft, J.B. (2010) Current Depression among Adults-United States, 2006 and 2008. Morbidity and Mortality Weekly Report, 59, 1229-1235.

[13] Hyun, J.K., Quinn, B.C., Madon, T. and Lustig, S. (2006) Graduate Student Mental Health: Needs Assessment and Utilization of Counseling Services. Journal of College Student Development, 47, 247-266. https://doi.org/10.1353/csd.2006.0030

[14] Adler, N.E., Boyce, T., Chesney, M.A., Cohen, S., Folkman, S., Kahn, R.L. and Syme, S.L. (1994) Socioeconomic Status and Health. American Psychologist, 49, 15-24. https://doi.org/10.1037/0003-066X.49.1.15 
[15] Anderson, C., Hildreth, J.A.D. and Howland, L. (2015) Is the Desire for Status a Fundamental Human Motive? A Review of the Empirical Literature. Psychological Bulletin, 141, 574-601. https://doi.org/10.1037/a0038781

[16] Kenrick, D.T., Griskevicius, V., Neuberg, S.L. and Schaller, M. (2010) Renovating the Pyramid of Needs: Contemporary Extensions Built upon Ancient Foundations. Perspectives on Psychological Science, 5, 292-314. https://doi.org/10.1177/1745691610369469

[17] Sapolsky, R.M. (2015) Stress and the Brain: Individual Variability and the Inverted-U. Nature Neuroscience, 18, 1344-1346. https://doi.org/10.1038/nn.4109

[18] Davis, J.A. (1956) Status Symbols and the Measurement of Status Perception. Sociometry, 19, 154-165. http://www.jstor.org/stable/2785629 https://doi.org/10.2307/2785629

[19] Cheng, J.T., Tracy, J.L., Foulsham, T., Kingstone, A. and Henrich, J. (2013) Two Ways to the Top: Evidence That Dominance and Prestige Are Distinct Yet Viable Avenues to Social Rank and Influence. Journal of Personality and Social Psychology, 104, 103-125. https://doi.org/10.1037/a0030398

[20] Singh-Manoux, A., Marmot, M.G. and Adler, N.E. (2005) Does Subjective Social Status Predict Health and Change in Health Status Better than Objective Status? Psychosomatic Medicine, 67, 855-861. https://doi.org/10.1097/01.psy.0000188434.52941.a0

[21] Macleod, J., Davey Smith, G., Metcalfe, C. and Hart, C. (2005) Is Subjective Social Status a More Important Determinant of Health than Objective Social Status? Evidence from a Prospective Observational Study of Scottish Men. Social Science and Medicine, 61, 1916-1929. https://doi.org/10.1016/j.socscimed.2005.04.009

[22] Adler, N.E. and Stewart, J. (2010) Health Disparities across the Lifespan: Meaning, Methods, and Mechanisms. Annals of the New York Academy of Sciences, 1186, 5-23. https://doi.org/10.1111/j.1749-6632.2009.05337.x

[23] Adler, N.E., Epel, E.S., Castellazzo, G. and Ickovics, J.R. (2000) Relationship of Subjective and Objective Social Status with Psychological and Physiological Functioning. Health Psychology, 19, 586-592. https://doi.org/10.1037/0278-6133.19.6.586

[24] Nielsen, F., Roos, J.M. and Combs, R.M. (2015) Clues of Subjective Social Status among Young Adults. Social Science Research, 52, 370-388. https://doi.org/10.1016/j.ssresearch.2015.02.006

[25] Giatti, L., Camelo, L.V., Rodrigues, J.F.C. and Barreto, S.M. (2012) Reliability of the MacArthur Scale of Subjective Social Status-Brazilian Longitudinal Study of Adult Health (ELSA-Brasil). BMC Public Health, 12, 1096.

https://doi.org/10.1186/1471-2458-12-1096

[26] Löwe, B., Kroenke, K. and Gräfe, K. (2005) Detecting and Monitoring Depression with a Two-Item Questionnaire (PHQ-2). Journal of Psychosomatic Research, 58, 163-171. https://doi.org/10.1016/j.jpsychores.2004.09.006

[27] Kroenke, K., Spitzer, R.L. and Williams, J.B.W. (2003) The Patient Health Questionnaire-2: Validity of a Two-Item Depression Screener. Medical Care, 41, 1284-1292. https://doi.org/10.1097/01.MLR.0000093487.78664.3C

[28] Zhang, Y., Liang, W., Chen, Z., Zhang, H., Zhang, J., Weng, X. and Zhang, Y. (2013) Validity and Reliability of Patient Health Questionnaire-9 and Patient Health Questionnaire-2 to Screen for Depression among College Students in China. Asia-Pacific Psychiatry, 5, 268-275. https://doi.org/10.1111/appy.12103

[29] Goodman, E., Maxwell, S., Malspeis, S. and Adler, N. (2015) Developmental Trajectories of Subjective Social Status. Pediatrics, 136, e640. 
https://doi.org/10.1542/peds.2015-1300

[30] McLaughlin, K.A., Costello, E.J., Leblanc, W., Sampson, N.A. and Kessler, R.C. (2012) Socioeconomic Status and Adolescent Mental Disorders. American Journal of Public Health, 102, 1742-1750. https://doi.org/10.2105/AJPH.2011.300477

[31] Scott, K.M., Al-Hamzawi, A.O. andrade, L.H., Borges, G., Caldas-de-Almeida, J.M., Fiestas, F. and Kessler, R.C. (2014) Associations between Subjective Social Status and DSM-IV Mental Disorders: Results from the World Mental Health Surveys. JAMA Psychiatry, 71, 1400-1408. https://doi.org/10.1001/jamapsychiatry.2014.1337

[32] Kearney, L.K., Draper, M. and Barón, A. (2005) Counseling Utilization by Ethnic Minority College Students. Cultural Diversity and Ethnic Minority Psychology, 11, 272-285. https://doi.org/10.1037/1099-9809.11.3.272

[33] Greer, T.M. and Chwalisz, K. (2007) Minority-Related Stressors and Coping Processes among African American College Students. Journal of College Student Development, 48, 388-404. https://doi.org/10.1353/csd.2007.0037

[34] Goodman, E., Adler, N.E., Kawachi, I., Frazier, A.L., Huang, B. and Colditz, G.A. (2001) Adolescents' Perceptions of Social Status: Development and Evaluation of a New Indicator. Pediatrics, 108, E31. https://doi.org/10.1542/peds.108.2.e31

[35] Rosenberg, M. and Pearlin, L.I. (1978) Social Class and Self-Esteem among Children and Adults. American Journal of Sociology, 84, 53-77.

https://doi.org/10.1086/226740

[36] Sweeting, H. and Hunt, K. (2015) Adolescent Socioeconomic and School-Based Social Status, Smoking, and Drinking. The Journal of Adolescent Health: Official Publication of the Society for Adolescent Medicine, 57, 37-45. https://doi.org/10.1016/j.jadohealth.2015.03.020

[37] Sweeting, H., West, P., Young, R. and Kelly, S. (2011) Dimensions of Adolescent Subjective Social Status within the School Community: Description and Correlates. Journal of Adolescence, 34, 493-504. https://doi.org/10.1016/j.adolescence.2010.06.001

[38] Festinger, L. (1954) A Theory of Social Comparison Processes. Human Relations, 7, 117-140. https://doi.org/10.1177/001872675400700202

[39] White, J., Langer, E., Yariv, L. and Welch IV, J. (2006) Frequent Social Comparisons and Destructive Emotions and Behaviors: The Dark Side of Social Comparisons. Journal of Adult Development, 13, 36-44. https://doi.org/10.1007/s10804-006-9005-0

[40] Nobles, J., Weintraub, M.R. and Adler, N.E. (2013) Subjective Socioeconomic Status and Health: Relationships Reconsidered. Social Science and Medicine, 82, 58-66. https://doi.org/10.1016/j.socscimed.2013.01.021

[41] Garbarski, D. (2010) Perceived Social Position and Health: Is There a Reciprocal Relationship? Social Science and Medicine, 70, 692-699.

https://doi.org/10.1016/j.socscimed.2009.11.007

[42] Schubert, T., Süssenbach, P., Schäfer, S.J. and Euteneuer, F. (2016) The Effect of Subjective Social Status on Depressive Thinking: An Experimental Examination. Psychiatry Research, 241, 22-25. https://doi.org/10.1016/j.psychres.2016.04.081

[43] Operario, D., Adler, N.E. and Williams, D.R. (2004) Subjective Social Status: Reliability and Predictive Utility for Global Health. Psychology and Health, 19, 237-246. https://doi.org/10.1080/08870440310001638098

[44] Destin, M., Richman, S., Varner, F. and Mandara, J. (2012) "Feeling" Hierarchy: The Pathway from Subjective Social Status to Achievement. Journal of Adolescence, 
35, 1571-1579. http://www.ncbi.nlm.nih.gov/pubmed/22796063 https://doi.org/10.1016/j.adolescence.2012.06.006

[45] Oyserman, D., Bybee, D. and Terry, K. (2006) Possible Selves and Academic Outcomes. Journal of Personality and Social Psychology, 91, 188-204.

https://doi.org/10.1037/0022-3514.91.1.188

[46] Rubin, M., Evans, O. and Wilkinson, R.B. (2016) A Longitudinal Study of the Relations among University Students' Subjective Social Status, Social Contact with University Friends, and Mental Health and Well-Being. Journal of Social and Clinical Psychology, 35, 722-737. https://doi.org/10.1521/jscp.2016.35.9.722 